\title{
Analysis of accounting risk based on derivative financial instruments
}

\author{
1,a Gao Lin \\ ${ }^{1}$ Qingdao Vocational and Technical College of Hotel Management, Qingdao, Shandong 266000, \\ China \\ asqxcy_xue@126.com
}

Keywords: Derivative financial instruments; accounting risk; statistics; regression

\begin{abstract}
By selecting the listed commercial banks as the sample and other related financial ratios which affect earnings and risks of commercial banks, its empirical analysis has been carried out using SPSS16.0. And then connect the index that investors are more concerned about in financial indicators with the main line- the proportion of derivative financial instruments. The use of derivative financial instruments could reduce bad loans of commercial banks through descriptive analysis and regression analysis of the results. Finally, the role of risk reversion and preserve or increase the value has been achieved.
\end{abstract}

\section{Introduction}

With the continuous development and modification of China's financial markets, the derivative financial instrument which is the financial innovation product has been getting closer and closer to us $[1,2,3]$. But due to the integration of the global economy, China's capital market closely linked to the world market. The fluctuation of some financial products such as interest rates, exchange rates, stocks, bonds could affect rise and fall of many companies, and even the stability of a country's economic order. The characteristics of derivative financial instrument such as leverage and price volatility determine the considerable risks of its own. Many investors tend to ignore the temptation of interest risk derivative transactions, and give companies huge economic losses. Various crises caused by derivative financial instruments make people begin to re-examine its role. If we would give full play to the positive role of derivative financial instruments, we should reduce its risk as much as possible. Accounting risk is one of the most critical risks. Therefore, how to reduce the risk plays an important role to maximize the positive function of derivative financial instruments. Therefore it is very necessary to explore the risks of derivative financial instruments accounting from this point.

By selecting the listed commercial banks as the sample and other related financial ratios which affect earnings and risks of commercial banks, its empirical analysis has been carried out using SPSS16.0. And then connect the index that investors are more concerned about in financial indicators with the main line- the proportion of derivative financial instruments. After observing the test value of this model could go through the critical value standard, making the classification of different financial indicators, from final disclosure in the financial reports, you could see whether the derivative financial instruments could avoid the risk of commercial banks and improve the benefits.

\section{The connotation of the derivative financial instruments accounting risk}

Derivative financial instrument is a bilateral contract or payment exchange agreement based on the future. Its value is taken or derived from the price of the relevant subject matter and its changes, which include but are not limited to stocks, bonds, currencies, interest rates, exchange rates and index [6]. The connotation of derivative financial instruments could be generalized into:(1) the value of derivative financial instruments will vary and change with the name of the subject matter and terms of payment. (2)an initial net investment or the required initial net investment has no request.(3): Net amount is required or permitted in the future. Derivative financial instrument does not have value in itself, but its price is changed with the underlying instrument. There are a wide variety of derivative financial instruments with flexible design. In accordance with their needs, companies could produce 
different derivative financial instrument varieties. As the market-based subject matter is in a constant state of change, buyers and sellers in most cases do not completely insight into all the factors that lead to changes in the market. Leverage is also the largest characteristic of derivative financial instruments.

Origin of derivative financial instruments is from avoiding risks. Avoiding risk is the most important function. Derivatives trading in particular floor trading has a large number of traders who will analyze and forecast price dynamics on the basis of collected information. They reach an agreement for sale by public auction to ensure the unity of the price in space and advance and coherence in time. The rentability of derivative transactions mainly includes the income from the operation and revenues from derivatives brokers.

Derivative financial instruments accounting risk is the combination between the instruments and accounting risks. Therefore it has the characters of the instruments and accounting risks. That is to say, Derivative financial instruments accounting risk poses the characters of objectivity, severity, uncertainty and uncontrollable nature from accounting risk. At the same time it also has high risk, financial leverage, uncertainty and other features from derivative financial instruments.

\section{Empirical Analysis of derivative financial instruments based on risk}

Sample Analysis: In this paper, 10 listed commercial banks in Shanghai and Shenzhen have been selected randomly. Put annual data from 2011 to 2013 as the object. And then finalize total of 30 samples in three years as the raw data for statistical models. Some commonly- used data indicators are used in this paper including earnings per share, the NPL ratio, loan provision ratio, ROE, capital adequacy ratio, etc. which could be obtained directly from basic financial data from the company in Securities Star and annual reports of listed commercial banks. But some financial data and ratios closely related to derivative financial instruments, for example, the value of the derivative financial instrument contracts, the weighted average rate of return risk assets, operating margin and others which need classification statistics and computing from the recent annual report 10 listed commercial banks. In this article, the collation of original data and calculation of ratios will use Excel2007. Descriptive statistics analysis and the test of regression model will be conducted by the use of the statistical software SPSS16.0.

Selecting and removing of variables: Selecting the common financial ratios which could reflect listed commercial bank profitability as explanatory variables, financial ratios related to derivative financial instruments as explanatory variables. By the replacement of the four explanatory variables in the statistical model, SPSS16.0 has been performed to do statistical analysis. And then significant analysis has been conducted by outputting results to determine whether significant explanatory variables could affect the explained variables or not. Finally, operation analysis on the final conclusions has been conducted to draw the conclusions on the status of derivative financial instruments in our country, the influence as well as recommendations.

Explanatory variables: X1: Derivatives / Total Assets (\%); X2: ROE (\%); X3: risk-weighted assets yield (\%); X4: NPL ratio (\%);

Variable being explained variables: Y1: Operating margin (\%); Y2: Capital Adequacy Ratio (\%); Y3: loan provision ratio (\%); Y4: earnings per share (RMB / share)

Descriptive statistical analysis: From Table 1, we can see that the maximum value of X1 (contract value of derivative financial instruments / total assets) was 24.54, the minimum is 1.95 , a standard deviation of 8.14333, which is easy to see that there is a great gap and volatility in the proportion of derivatives financial instruments holding by China's listed commercial banks. The skewness of X2 (ROE) indicates that the span is not great but its volatile is great. And there is great difference in ROE for different listed commercial banks. X3 (return on risk-weighted assets) distributes in right-skewed. It is not difficult to see from the indicators that its volatility rate of return is not great when the listed commercial banks make use of speculative risk assets. X4 indicates that there is no much difference in bad loan from listed commercial banks and the volatility is small. Y1 (operating margin) indicates that there is a great difference in terms of profitability and volatility is also very large. When the skewness is less than 0 , the trend is left-skewed distribution. Y2 (capital adequacy ratio) indicates that 
all listed commercial banks have already met the requirements and the volatility is very small. So the capital adequacy ratio is a more stable indicator. Volatility of Y3 (loan provision ratio) is not large. But the span of each listed commercial banks is relatively large. So there is a certain gap for the management of non-performing loans. Y4 (EPS) shows that the minimum is 0.32 , the maximum is 2.66, a standard deviation is 0.60201 and the skewness is 1.301 . The overall volatility is not great and the overall trend is right-skewed, which indicate that the individual listed commercial banks profitability and stock investment value are relatively low.

Table 1 Commercial Banks descriptive statistics

\begin{tabular}{|l|l|l|l|l|l|l|l|}
\hline & N & Min & Max & Mean & \multicolumn{2}{l|}{ Std. Deviation } & \multicolumn{2}{l|}{ Skewness } \\
\hline Y1 & 30 & 28.09 & 57.03 & 48.3103 & 7.10198 & 1.248 & 0.427 \\
\hline Y2 & 30 & 10.02 & 13.68 & 11.6610 & 0.94002 & .227 & 0.427 \\
\hline Y3 & 30 & 0.86 & 2.82 & 2.0020 & 0.51639 & -0.449 & 0.427 \\
\hline Y4 & 30 & 0.32 & 2.66 & 0.9597 & 0.60201 & 1.301 & 0.427 \\
\hline X1 & 30 & 1.95 & 24.54 & 12.0113 & 8.14333 & 0 & 0.427 \\
\hline X2 & 30 & 13.04 & 24.46 & 18.8513 & 2.80770 & 0.360 & 0.427 \\
\hline X3 & 30 & 0.87 & 2.68 & 1.7664 & 0.42734 & 0.303 & 0.427 \\
\hline X4 & & 0.38 & 1.54 & 0.9127 & 0.34580 & 0.350 & 0.427 \\
\hline
\end{tabular}

Analysis of regression: The first linear equation is

$\mathrm{Y} 1=\beta 0+\beta 1 \mathrm{X} 1+\beta 2 \mathrm{X} 2+\beta 3 \mathrm{X} 3+\beta 4 \mathrm{X} 4+\varepsilon$.

From Table 2, we first observe the goodness of fit R2 is 0.869 , relatively close to 1 . So we could say that the initial linear regression model is feasible. In this paper, when we test the significance, we adopt $\alpha$ is 0.05 .firstly, we test F. Since the number of samples in the model $n$ is 30, the explanatory variable number is 4 , the distribution from $F$ to $F$ is $(4,25)$. From statistical data table, we could acquire that $(4,25)$ equals to 2.06 . And from the above table, it is shown that $F$ equals to 41.483 which is less than 2.06 and $\mathrm{P}$ is 0 which is less than0.05. Therefore linear regression line is conformed to conditions and the regression equation is:

Table 2 Result of Linear equation structure

\begin{tabular}{|c|c|c|c|c|c|}
\hline $\begin{array}{lr} & \text { Mod } \\
\text { el } & \\
\end{array}$ & $\mathrm{R}$ & R Square & $\begin{array}{l}\text { Adjusted R } \\
\text { Square } \\
\end{array}$ & $\begin{array}{l}\text { Std. Error of } \\
\text { the Estimate }\end{array}$ & Durbin-Watson \\
\hline 1 & $.932^{\mathrm{a}}$ & .869 & .848 & 2.76782 & 2.026 \\
\hline
\end{tabular}

After removing the independent variable X2, the linear regression model has been proposed. The result is shown in Table 3. X1 (derivatives / Total assets) has played a positive relationship role for Y1 (operating margin), but its weight ratio is much smaller than X3 (return on risk-weighted assets). The more X4 (NPL ratio) is, operating profit margin of commercial banks is lower. The coefficient in the model is negative. Therefore, the equation has realistic meaning. So the proportion of derivative financial instruments in commercial banks' total assets has positive impact on operating profit ratio. But the impact may not be very large. Because each listed commercial banks have strict rules on the risk assets, it cannot have substantial impact on the listed commercial banks operating margin from the status of the current use of derivative financial instruments.

Table 3 Result of the regression equation of Y1 Table 4 Result of the regression equation of Y2
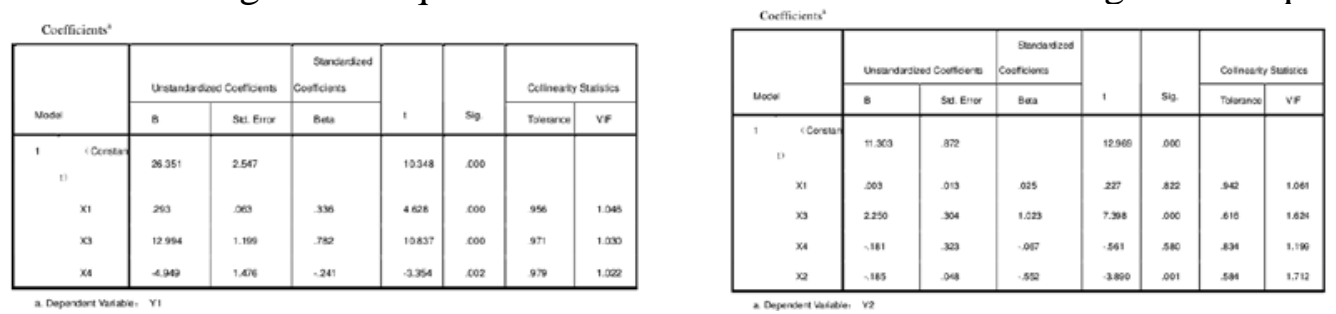

From Table 4, for linear regression of Y2 is a failure, because the data obtained from X1 t=0.227 which is less than critical value $=\mathrm{t} 0.025(25)=2.06$. The entire linear regression equation isn't very significant. So it does not have statistical significance. From the results, I can safely infer that Y2 
(capital adequacy ratio) is mandatory. Every listed commercial bank should reach the standard. Therefore, no matter how much X1 (derivative financial instruments / total assets) is, it could not affect the financial law. The regression model to X1 (derivatives / Total assets) is pointless.

Table 4 Result of the regression equation of Y3

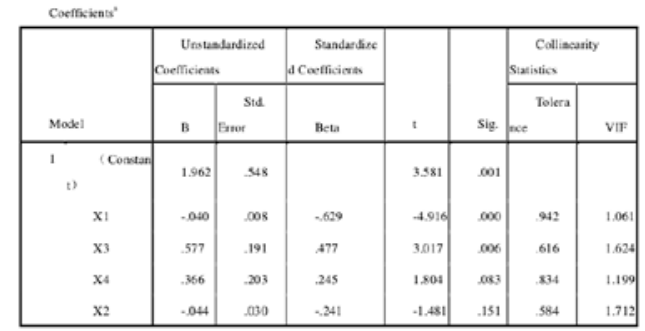

Table 5 Result of the regression equation of Y4

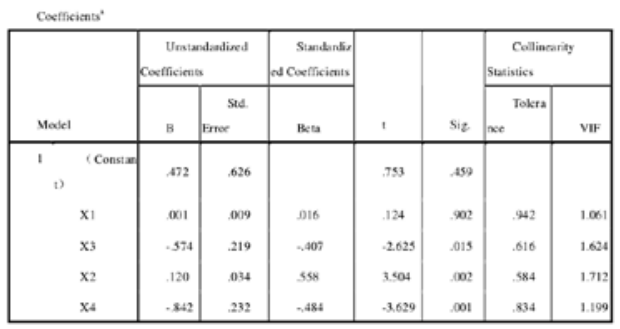

As can be seen from Table 4, only the absolute values of t from X1 and X3 are respectively 4.627 and 2.544 which are less than 2.052. At the same time, the values $\mathrm{P}$ of $\mathrm{X} 1$ and $\mathrm{X} 3$ are respectively 0.000 and 0.017 which are less than 0.05 . Therefore removing a variable in last step is effective. X1 (derivatives / Total assets) plays a reverse effect on Y3 (loan provision ratio), namely the larger of proportion of derivative financial instruments holding by listed commercial banks is, the smaller Y3 (loan provision ratio) is. at the same time, provision for diminution in value will reduce. So the model supports the reality of the theoretical results. Second, X3 (risk-weighted assets yield) produces positive effect on Y3 (loan provision ratio). The higher net profit from risky assets, the proportion of provision for diminution in value in the loans will be greater. It is indicated that the scale of the loan is reduced. Because investment in other risky assets can get more revenue and the loan provision ratio is also reduced, the independent variable also has realistic significance.

From Table 5, the linear regression of Y4 is a failure, because the data $\mathrm{X} 1(\mathrm{t})$ is 0.124 which is less than the critical value $(\mathrm{t} 0.025(25)=2.06)$. This is not very significant in the linear regression equation. Therefore it has no practical statistical significance. We could not conclude that Y4 has no linear relationship with the other four independent variables. Because coefficient $\beta 1$ is 0 , the initial regression equation has no significance. From the result of the regression model, I can safely infer that Y4 (EPS) is determined by after-tax profits of listed commercial banks and ordinary shares. And the derivative financial instruments can affect the molecular weight, but it hasn't too direct impact on shares of the listed commercial banks. Therefore, whether listed commercial banks to hold how much $\mathrm{X} 1$ (derivatives / total assets), there is little effect.

\section{Accounting income, risk and disclosure}

The scale of derivative financial instruments has played a positive role in operating margin and brings returns for commercial banks. From the regression results by earnings, although the effects of instrument on earnings are subtle, there is the rising trend of its scale.

From loan provision ratio, we can see that derivative financial instruments have inhibiting effect on the decrease in loans of commercial banks. That is to say, the use of derivative financial instruments could reduce bad loans of commercial banks to realize risk reversion and preserve or increase the value. The development of derivative financial instruments has real economic significance. To some extent, the use of derivative financial instruments could reduce economic turmoil and provide some protections for the world economy stable operation.

Establish a good model of quantitative analysis. Changes in derivative financial instruments are the key factor in its complex and difficult to control. Therefore the establishment of a quantitative analysis model by the use of computer technology is a better solution to track changes in derivative financial instruments. To improve the company's internal risk control department, reduce operational risks, we should carry out authorized approval and control strictly for the derivative financial instruments. And eliminate the use of some characteristics such as change and difficult to measure to do any illegal operations to ensure that real-time monitoring of their internal risk control department, and constraint the operator behavior. The incompatible positions should separate with each other. For the staff in internal risk control departments, some prevention measures such as regular rotation should be implemented. 


\section{Conclusions}

Because of the economic operation situation in the real market and investor's transaction demand, the rules of derivative financial instruments could be able to improve continuously. so the external economic environment could have influence on derivative financial instruments which could serve the market. By selecting the listed commercial banks as the sample and other related financial ratios which affect earnings and risks of commercial banks, its empirical analysis has been carried out using SPSS16.0. And then connect the index that investors are more concerned about in financial indicators with the main line- the proportion of derivative financial instruments. The use of derivative financial instruments could reduce bad loans of commercial banks through descriptive analysis and regression analysis of the results. Finally, the role of risk reversion and preserve or increase the value has been achieved. After observing the test value of this model could go through the critical value standard, making the classification of different financial indicators, from final disclosure in the financial reports, you could see whether the derivative financial instruments could avoid the risk of commercial banks and improve the benefits.

\section{References}

[1] Zhang Xiuyun. Research on Financial derivatives risk of accounting regulation [D].Hei Longjiang: Northeast Forestry University,2010.

[2] Liu Jing. Review of Chinese derivative financial instruments [J]..Journal of Shanghai Lixin accounting college,2005, (05) : 25-28.

[3] Wang Qibo. The characteristics of the derivative financial instruments accounting standards development[J]. Journal of Shanxi university of finance and economics,2006,28(01): 125-127.

[4] Shan Rong. The disclosure of financial derivatives risk information: Based on the research analysis of the subprime crisis [J].China Business,2010,(01): 43-44.

[5] Guan Sujuan. The identification and control of Enterprise accounting risk [J]. China's collective economy,2010, (08) : 149-151..

[6] Wu Lingling. The disclosure research on Derivative financial instrument risk [J]. Management \& Technology of SME,2009, (08) : 76-76.

[7] Li Changyan. A brief analysis of derivative financial instruments accounting treatment [J]. Friends of Accounting,2009, (03) : 64-66.

[8] Zhang Tingting. The studies on derivative financial instruments accounting [D].Beijing: Capital University of Economics and Business,2010.

[9] Zhang Qingyi. The research on Accounting problems of derivative financial instrument risk [D].Liao Ning: Northeast University of finance,2007. 